\title{
Opiáceos, Opióides de ação analgésica e antagonistas
}

\section{Opiate, Opioid analgesics and antagonists}

\author{
Dalva Trevisan Ferreira ${ }^{1}$; Milton Faccione ${ }^{1}$
}

\begin{abstract}
Resumo
Opiáceos e opióides são importantes fármacos utilizados no tratamento da dor. Eles estão relacionados à adicção e a depressão respiratória, efeitos colaterais que limitam o seu uso. Este trabalho descreve as principais classes de fármacos agonistas e antagonistas aos receptores $(\alpha, \delta, \kappa)$. Os principais fármacos são apresentados enfatizando-se relação versus atividade e reações de biotransformações.

Palavras-chave: Opiáceos. Opióides de ação analgésica. Relação estrutura. Atividade. Biotransformações.

Abstract

Opiate and opioid analgesics are important drugs in the treatment of pain. They are associated with addiction and respiratory depression, side effects which limit their clinical usefulness. This paper describes the main classes of agonists and antagonists to opioid receptors $(\alpha, \delta, \kappa)$. The main drugs will be shown emphasizing the structure-activity relationship, as well as biotransformation reactions.
\end{abstract}

Key words: Opiate and opioid analgesics. Structure-activity relationship. Activity. Biotransformations.

\footnotetext{
1 Universidade Estadual de Londrina, Londrina- PR. CCE: Departamento de Química. Laboratório de Pesquisa em Moléculas Bioativas.
} E-mail: dalva@uel.br. 


\section{Introdução}

Os hipnoanalgésicos são fármacos que deprimem o Sistema Nervoso Central (SNC) eliminando ou reduzindo a sensação de dor, sem causar a perda de consciência. Eles agem complexando-se com múltiplos receptores estereoespecíficos, em muitos locais do SNC, no sistema nervoso periférico e no sistema nervoso entérico. A morfina foi descoberta pelo farmacêutico alemão Sertürner em 1803 e a definição de sua estrutura foi realizada por Robinson. Os principais agentes utilizados na terapia da dor são os opiáceos (derivados do ópio) e os opióides derivados sintéticos com ação semelhante à morfina (CHRISTOFFERS et al., 2003) e (ALDRICH, 1996).

\section{Receptores de Opióides e seus mecanismos efetores}

Com base no perfil farmacológico, o sistema opióide foi caracterizado pela presença de três principais receptores e subtipos acoplados à proteína G:mu( $\mu$, MUR), capa (k, KOR) e delta ( $\delta$, DOR).
Todos eles são bloqueados pela naloxona, um antagonista de receptores de opióides. A morfina, a cetociclazocina e a $\mathrm{N}$-alilmetazocina representam os ligantes protótipos dos receptores $\mu, \kappa$ e $\delta$ respectivamente. A ativação dos receptores opióides $\mu, \delta, \kappa_{1}$, e $\kappa_{3}$ nos neurônios endógenos, apresenta inúmeras conseqüências: a) a inibição da atividade da adenilciclase levando a uma redução da concentração intracelular de monofosfato cíclico de adenosina (cAMP), b) a abertura dos canais de $\mathrm{K}^{+}$, causando a hiperpolarização do neurônio nociresponsivo, com conseqüente redução da excitabilidade e c) o bloqueio da abertura dos canais de $\mathrm{Ca}^{++}$voltagem - dependentes, inibindo a liberação do glutamato e da substância $P$ pelos terminais aferentes primários. Estes são os mecanismos que explicam o bloqueio opióide da liberação de neurotransmissores e da transmissão da dor em várias vias neuronais (GUNION; MARCHIONNE; ANDERSON, 2004), (BECKER et al., 2004), (CONTET; KIEFFER; BEFORT, 2004), (SNYDER, 2004), (FRIES, 1995) e (REISINE; PASTERNAK, 1996).

\section{Quadro 1}

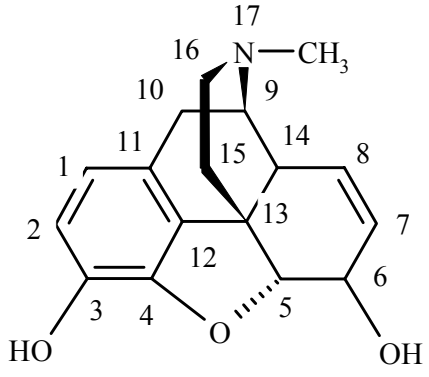

morfina

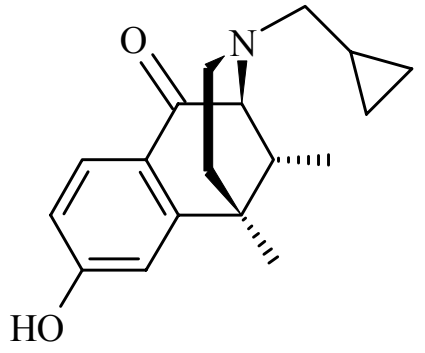

cetociclazocina

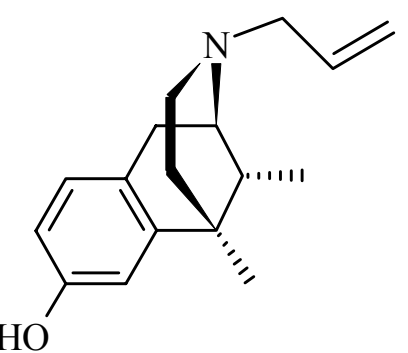

SKF 10.047 (N-alilmetazocina)

\section{Hipnoanalgésicos}

Estes fármacos podem ser classificados em exógenos (Figura 1) e endógenos (Figura 2). Os analgésicos exógenos apresentam em comum certas características que são: a) um grupo amino terciário separado de um anel aromático por dois átomos. b) um átomo de carbono quaternário e c) um anel fenílico ou isóstero ligado ao átomo de carbono. O grupo farmacofórico N-metil- $\gamma$-fenilpiperidina, estrutura (a), Figura 2, é o responsável pela ação farmacológica 
desta família de substâncias. As encefalinas (opióides endógenos) e certos hipnoanalgésicos não apresentam o anel piperidínico, contudo, apresentam um resíduo tiramínico, estrutura (b) Figura 2, também presente nos opiáceos e em muitos de seus análogos sintéticos (FRIES, 1995), (RESINE; PASTERNAK, 1996), (ZARRINDAST; REZAYOF, 2004), (SOIGNIER et al., 2004), e (WILLET, 1998).
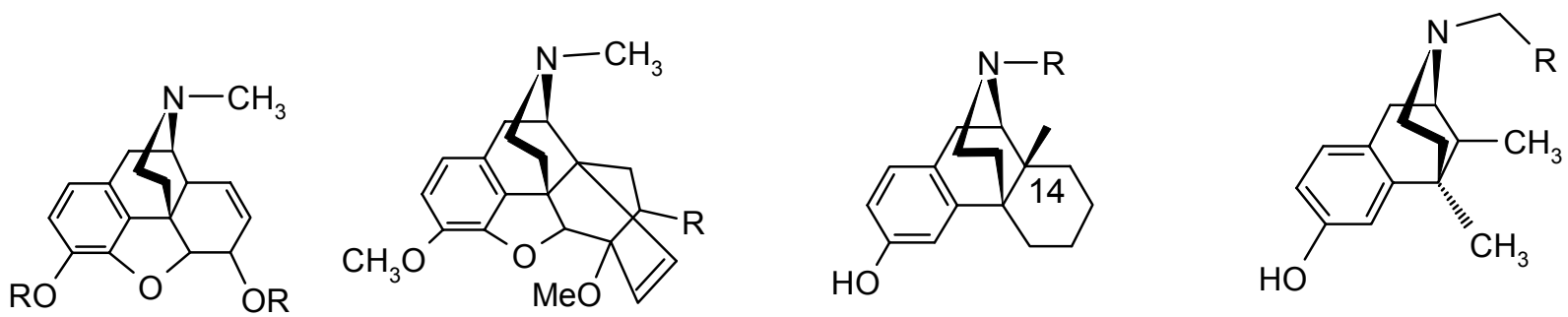

morfina e derivados

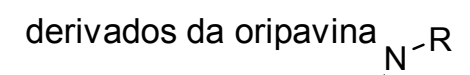

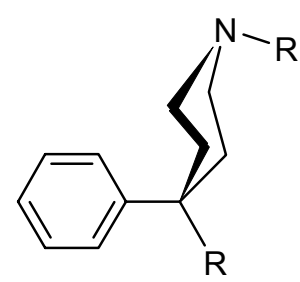

fenilpiperidinas

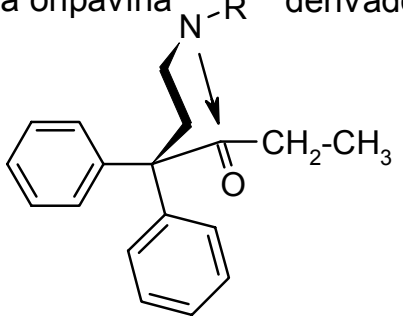

difenilpropilamina e derivados metanobenzazocinas e

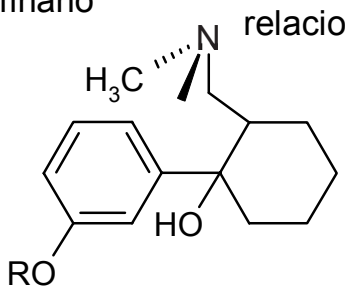

derivados do cicloexanol

Figura 1. Estruturas gerais dos hipnoanalgésicos opióides exógenos.

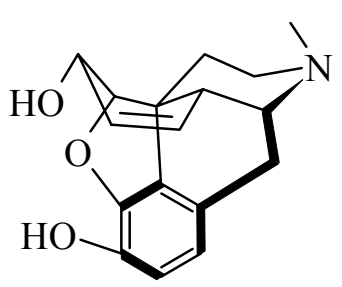

Morfina

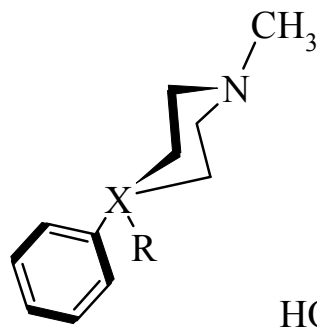

(a)

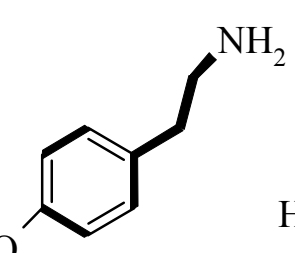

(b)

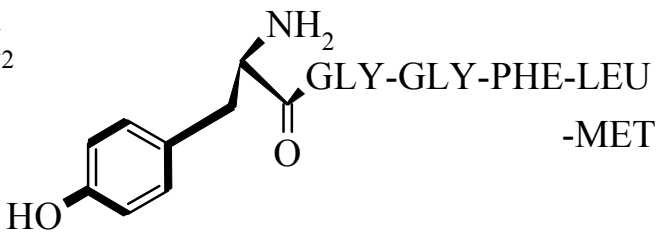

Encefalinas

Figura 2. Características estruturais comuns.

\section{Morfina e derivados}

A morfina é o principal alcalóide do ópio, o qual é obtido das cápsulas das sementes da papoula, Papaver somniferum, contendo mais de 50 alcalóides. Ela é o opióide protótipo e o de maior utilização como analgésico para os receptores $\mu$. A molécula possui cinco centros assimétricos e uma estereoquímica correspondente a 5R, 6S, 9R, 13S e
14R. O isômero natural da morfina é levorotatório (-). O isômero dextrorotatório $(+)$ já foi sintetizado, mas é destituído de atividade analgésica. As principais relações versus atividade analgésica e as reações de biotransformações estão representadas nas Figuras 3 e 4 respectivamente.(ALDRICH, 1996), (ANDERSEN et al., 2004), (EVANS; LENZ; LESSOR, 1989), (CHRISTOFFERS et al.,2003). 


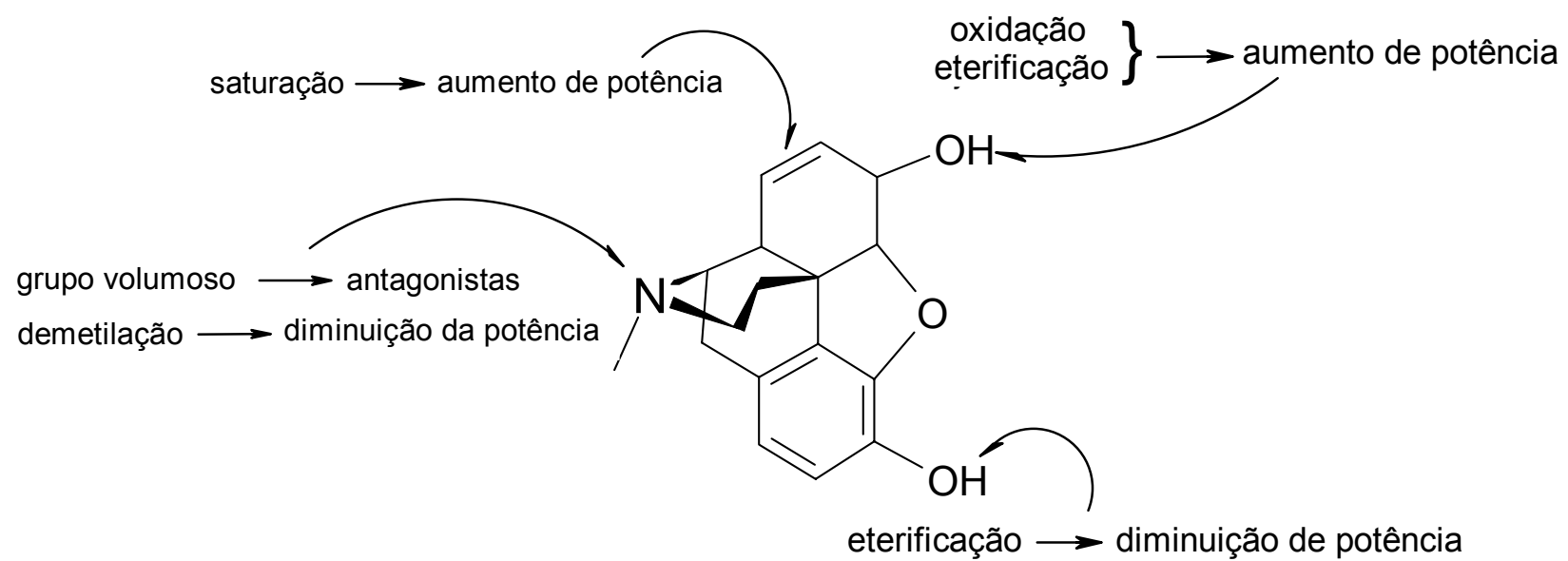

Figura 3. Relação estrutura versus atividade analgésica da morfina.
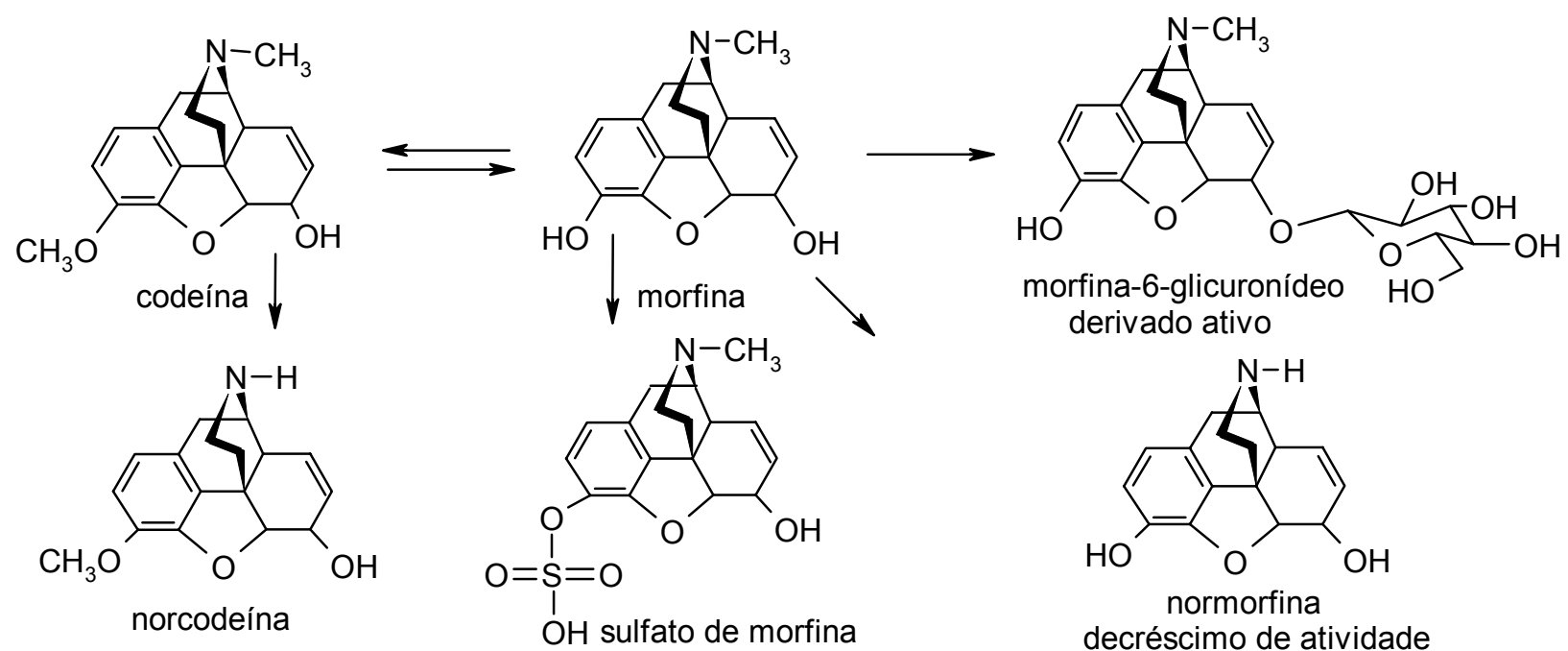

Figura 4. Principais caminhos de biotransformações da morfina.

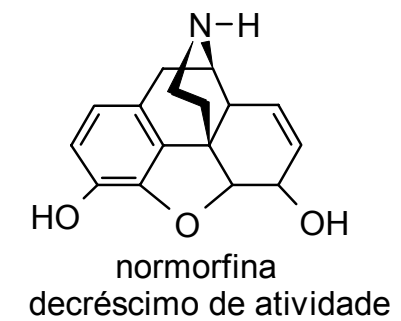

\section{Derivados da Oripavina os endoderivados}

Os representantes desta classe são conhecidos como opiáceos-6,14-endoeteno ou adutos de DielsAlder, e apresentam alta potência analgésica, que em alguns casos, chega a ser 1000 vezes maior do que a da morfina. Exemplos de fármacos desta classe são: a acetorfina, a aletorfina, a buprenorfina, a diprenorfina e a etorfina. A buprenorfina é um opióide de ação mista que tem alta afinidade pelos receptores $k$ e também funciona como antagonista nos receptores $k$ e a sua potência analgésica é de 25-40 vezes maior do que a da morfina. Ela tem a habilidade em atenuar os efeitos fisiológicos e psicológicos de outros opióides e o seu tempo de ação é prolongado, pela lenta dissociação dos receptores e o uso de dose diária menor. Os efeitos da retirada do fármaco, em relação à síndrome de abstinência, são pequenos e, dessa forma, ela torna-se um fármaco apropriado para o tratamento de detoxificação em dependentes de heroína. Ela age como indutor da apoptose, possui ação citotóxica o que indica sua potencial ação na quimioterapia do câncer (SOBEL et al., 2004), (DAVIDS; GASTPAR, 2004), (SPORER, 2004), (JAFFE; O’KEEFFE， 2003), (KUGAWA; MATSUMOTO; AOKI, 2004) e (POIRIER et al., 2004). 


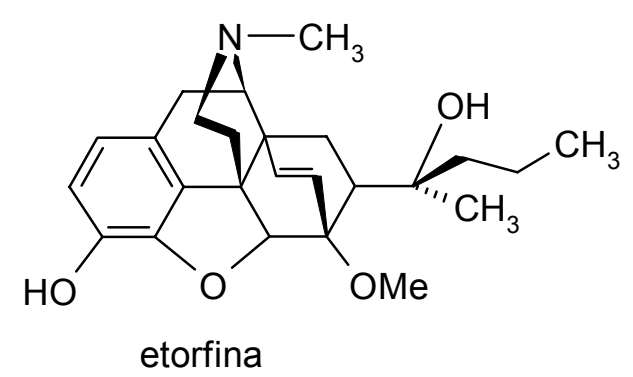

Figura 5. Exemplo de derivados da oripavina.

\section{Morfinanos E 2,6-Metano-3-Benzazocinas e relacionados}

Os morfinanos são opióides sintéticos derivados do levorfanol ou do dextrorfano e a sua atividade analgésica é encontrada exclusivamente nos isômeros levo. Os principais representantes desta classe são o levorfanol e o butorfanol. A ciprodima é um

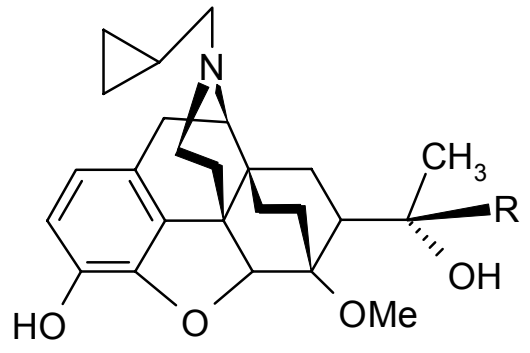

$\mathrm{R}=\mathrm{CH}_{3}$ diprenorfina $\mathrm{R}=\mathrm{C}\left(\mathrm{CH}_{3}\right)_{3}$ buprenorfina

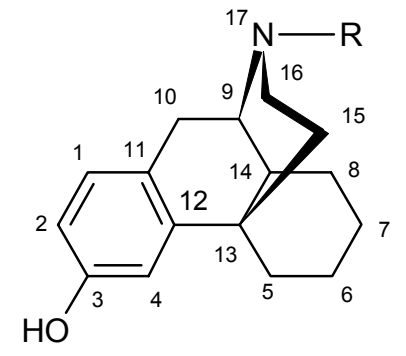

$\mathrm{R}=\mathrm{CH}_{3}$

$\mathrm{R}=\mathrm{CH}_{2}-\mathrm{CH}=\mathrm{CH}_{2}$ levalorfano

$\mathrm{R}=$ ciclopropilmetil ciclorfano

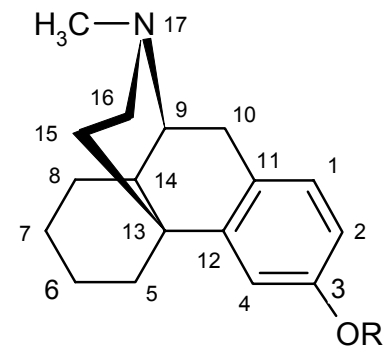

$\mathrm{R}=\mathrm{H} \quad$ dextrorfano

$\mathrm{R}=\mathrm{CH}_{3}$ dextrometorfano

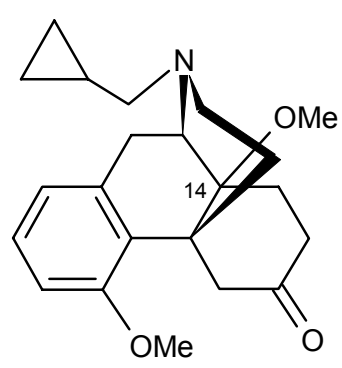

ciprodima

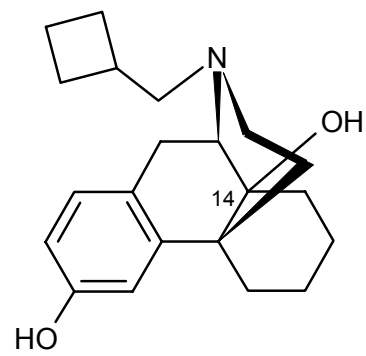

butorfanol

Figura 6. Exemplos de morfinanos
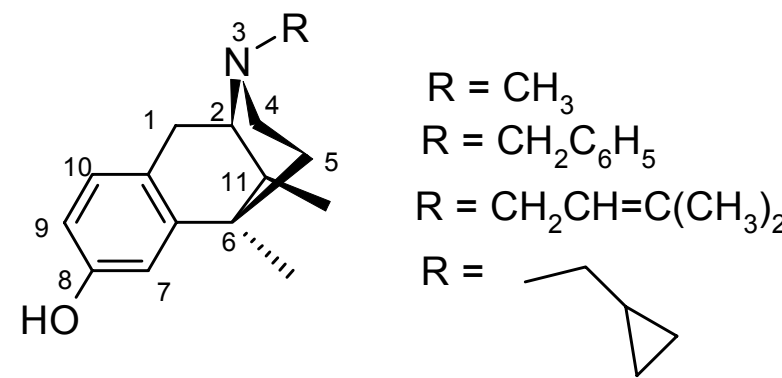

metazocina

fenazocina

pentazocina

ciclazocina

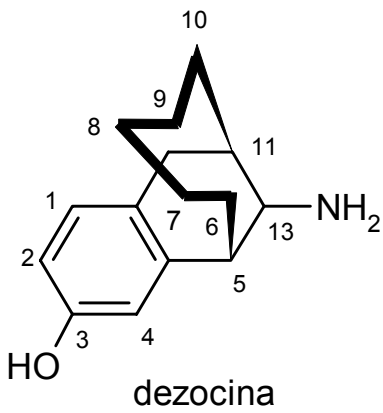

Figura 7. Exemplos de 2,6-metanobenzazocinas (benzomorfanos) e derivados. 


\section{Fenilpiperidinas e relacionados}

A petidina é o protótipo desta classe agindo predominante nos receptores $\mathrm{m}$ agonistas. A sua passagem no SNC é em torno de 600 vezes maior, em concentração, do que a morfina. Ela exerce efeitos farmacológicos diversos: hipnoanalgésico, espasmolítico, anestésico geral e anti-histamínico suave. A utilização deste fármaco tem diminuído em razão dos efeitos tóxicos de um dos seus metabólitos (nor-meperidina) e pela presença de um contaminante gerado pela degradação hidrolítica da função éster produzindo o N-metil-4-fenil-1,2,3,6-tetraidropiridina (MPTP). A nor-meperidina é hepatotóxica e irritante do sistema nervoso central enquanto o MPTP causa efeitos severos a este sistema, semelhantes aos produzidos pelo mal de Parkinson (GERRA et al., 2004; QUAGLIA et al., 2003; KESKIN et al., 2003; PANDA et al., 2004).

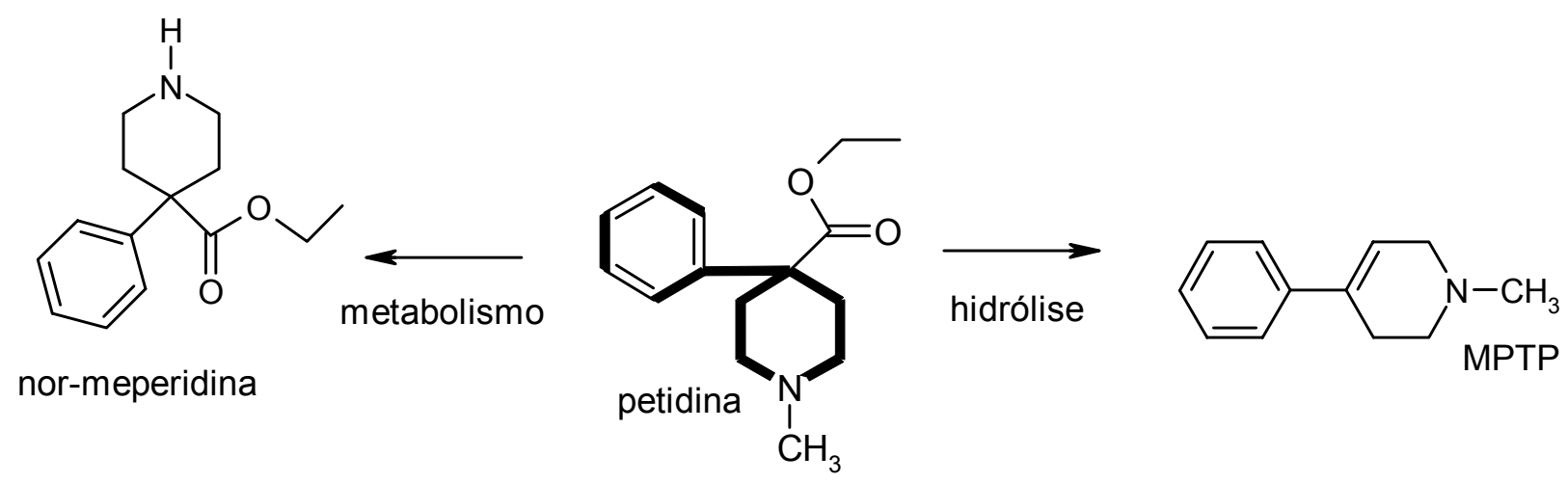

Figura 8. Fenilpiperidinas, meperidina (petidina): produtos de metabolismo e de hidrólise.

\section{Fenilpropilaminas}

Os representantes dessa classe são: a metadona (6-dimetilamino-4,4-difenil-3-heptona) e o dextropropoxifeno. A metadona é um opióide agonista sintético importante em saúde pública, sendo amplamente utilizado na prevenção da síndrome de abstinência de opióides. Como analgésico, é aproximadamente, duas vezes mais potente que a morfina. A molécula da metadona é quiral. A R-(-) metadona tem alta afinidade pelos receptores $\mu$ de opióide. A metadona apresenta um tempo de eliminação maior e a sua potência analgésica é 50 vezes maior do que a do isômero $\mathrm{S}-(+)$. Por outro lado, o isômero $\mathrm{S}-(+)$ tem maior ação imunossupressora. As biotransformações estão representadas na Figura 9. O $l$ - $\alpha$-acetilmetadol (LAAM) foi aprovado para uso em programas de manutenção do tratamento de adictos em heroína. Ele atua convertendo-se em metabólitos ativos, o que explicaria o início lento e a duração prolongada de sua ação. $\mathrm{O}$ isômero $d$ - $\alpha$-acetilmetadol é inativo (WHITTINGTON; SHEFFELS; KHARASCH, 2004; HUTCHINSON; SOMOGYI, 2004; NANOVSKAYA et al., 2004; FERRARI et al., 2004). 


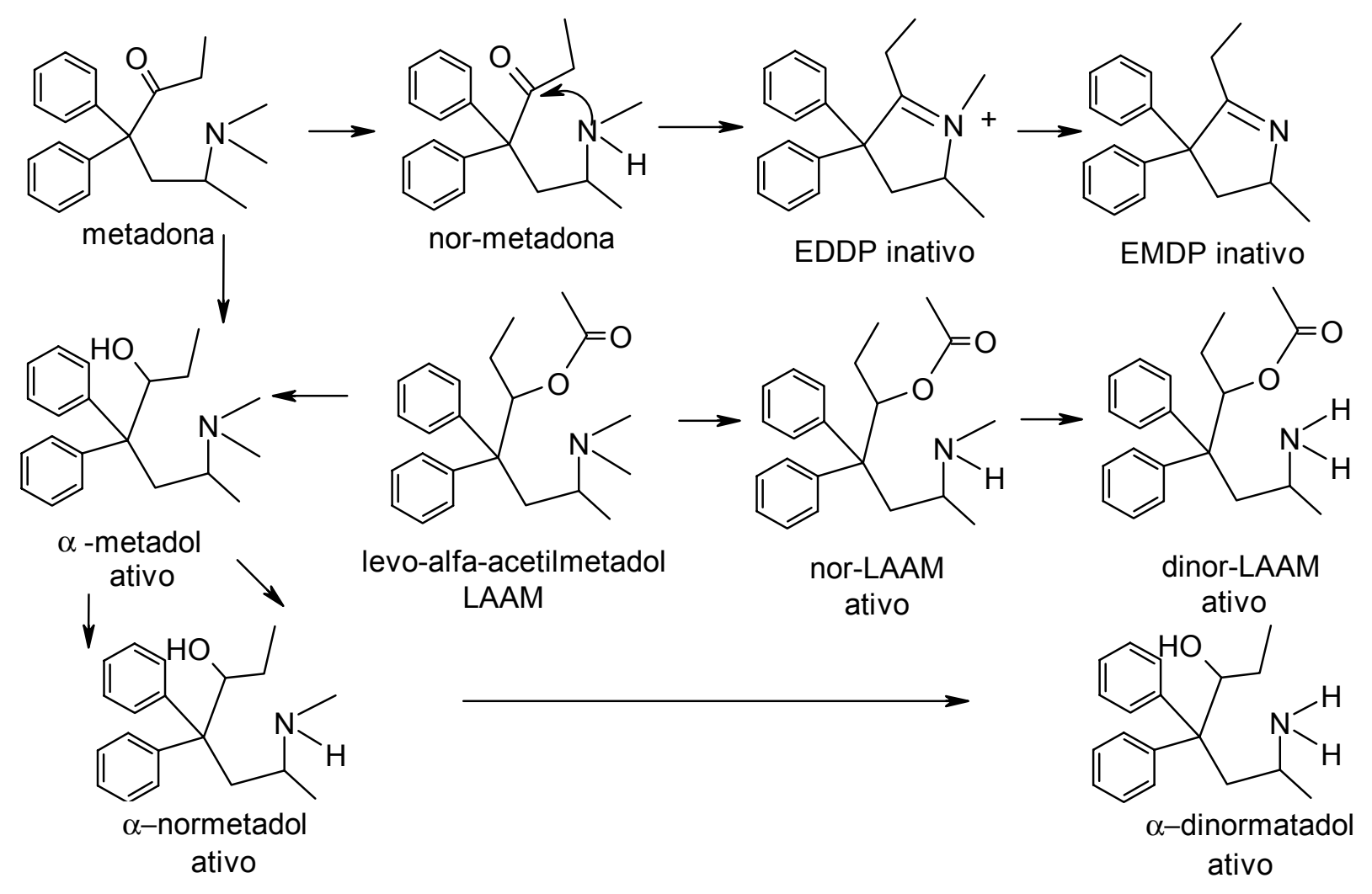

Figura 9. Metabolismo da metadona e do LAAM

\section{Derivados do Ciclohexanol}

O principal representante dessa classe é o (1RS, 2RS)-2-[(dimetilamino)-metil]-1-(3-metoxifenil)cicloexanol - (tramadol). Ele é utilizado no tratamento de dores (moderadas a intensa). O isômero $(+)$ é um agonista seletivo para os receptores $\mu$ de opióides e atua inibindo a reabsorção da serotonina aumentando a sua concentração no cérebro. Já o isômero (-) inibe a reabsorção da norepinefrina. $\mathrm{O}$ tramadol tem sido estudado e apresentado resultados positivos para sua utilização como antidepressivo. As biotransformações estão representadas na Figura 10. Os principais efeitos colaterais são a depressão respiratória e os efeitos cardiovasculares. Os estudos atuais revelam que mais de 26 casos de mortes estão associadas à utilização deste fármaco em combinação com os benzodiazepínicos (REITZ et al., 1995), (KOWALUK; ARNERIC, 1998), (FARONGÓRECKA et al., 2004; CAMPANERO et al., 2004; LEHTONEN et al., 2004; KOROLKOVAS, 1988; CLAROT et al., 2004; PAIVA; LOBO; CHAINHO, 2003; CLAROT, 2003 ). 


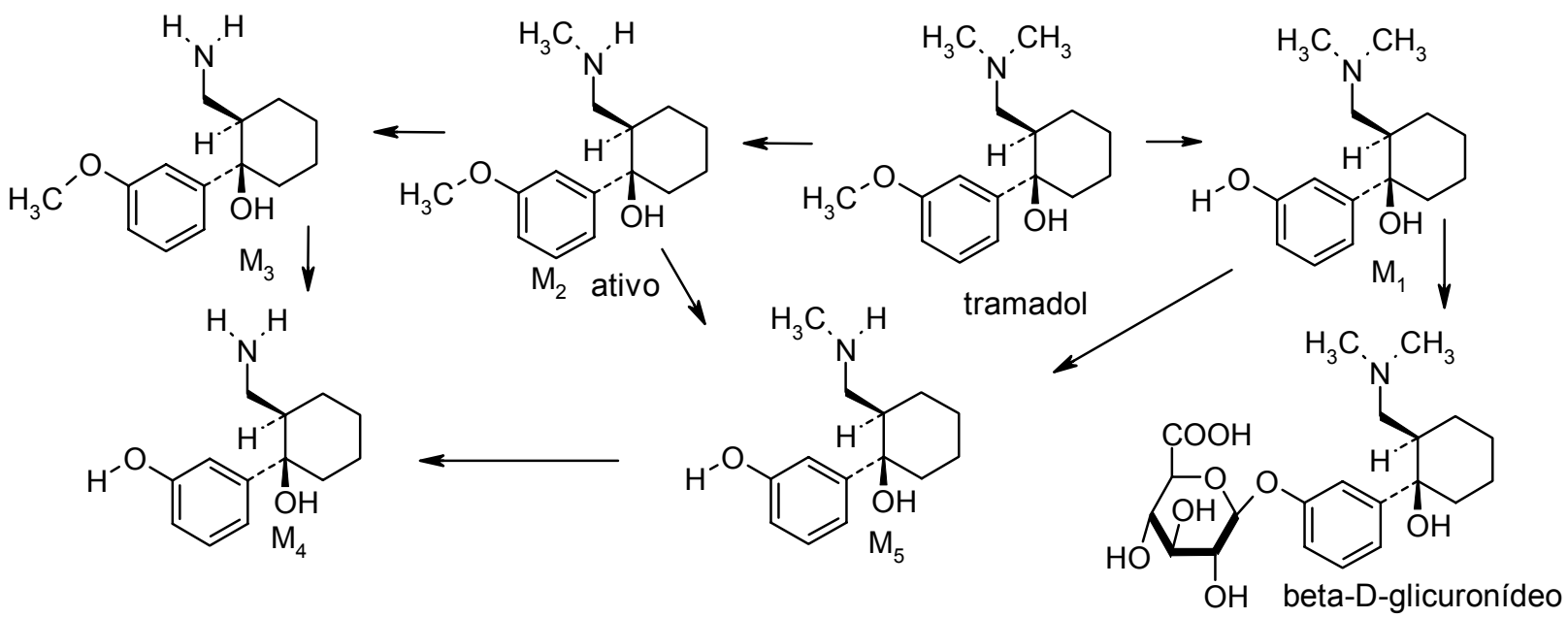

Figura 10. Estruturas do tramadol e de seus principais metabólitos.

\section{Efeitos adversos e colaterais e perspectivas futuras}

As múltiplas interações dos opióides com os receptores $(\alpha, \mu, \mathrm{e} \kappa)$ contribuem para o aparecimento de efeitos colaterais associados ao efeito analgésico. Estes efeitos incluem dependência física e psíquica, tolerância, imunosupressão, depressão respiratória, constipação, vômitos, náuseas, distúrbios cardiovasculares, tonturas, alterações do humor, retenção urinária, prurido, alterações da memória e do aprendizado e alterações do apetite. Eles podem causar a síndrome de abstinência, característica de opióides. Apesar dos progressos ocorridos no entendimento de como os opióides interagem com os ligantes produzindo os efeitos farmacológicos e as altas seletividades obtidas, a obtenção de um analgésico com alta potência, similar a morfina, e desprovido dos efeitos indesejáveis ainda continua sendo um desafio (GUNION;
MARCHIONNE; ANDERSON, 2004; WOODY et al., 2003; KOWALUK; LYNCH; JARVIS, 2000; EMMERSON et al., 2004).

\section{Antagonistas de Hipnoanalgésicos}

Os antagonistas de opióides evitam, ou eliminam, a depressão respiratória provocada pela administração de analgésicos opióides. Alguns desses fármacos podem ser usados em tratamentos de indivíduos com intoxicação causada por opióides, em testes de dependência narcótica e nos casos de alcoolismo. A simples troca de um radical $\mathrm{N}$-metil por um radical $\mathrm{N}$-alil, $\mathrm{N}$-ciclopropilmetil (CMP) ou $\mathrm{N}$-ciclobutilmetil (CBM), pode alterar a ação agonista potente para a ação antagonista potente. Estes derivados induzem uma alteração conformacional no receptor ou bloqueiam certas áreas essenciais do receptor, impedindo a interação com o receptor (ALDRICH, 1996; CRAFT; MCNIEL, 2003; CHEN et al., 2004). 


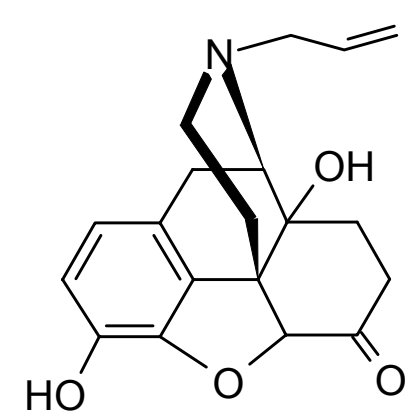

naloxona

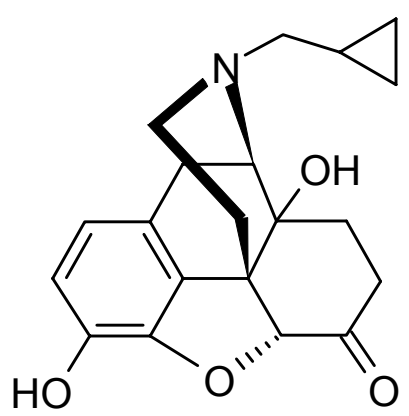

naltrexona

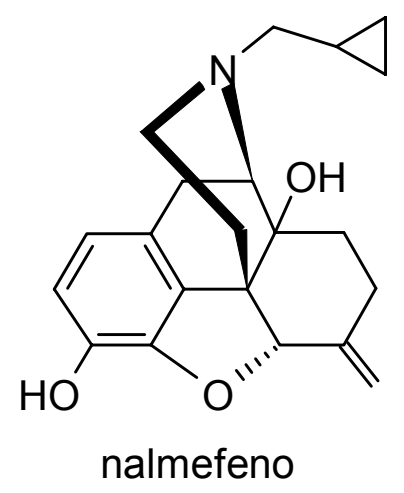

Figura 11. Antagonistas puros de opióides.
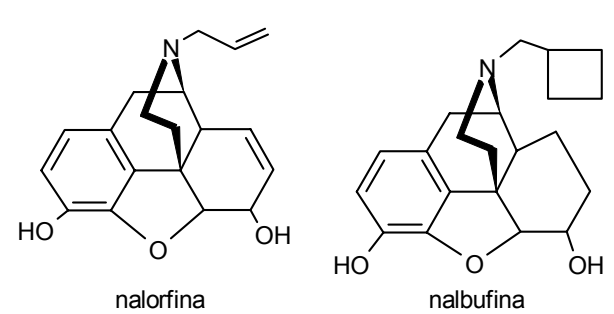
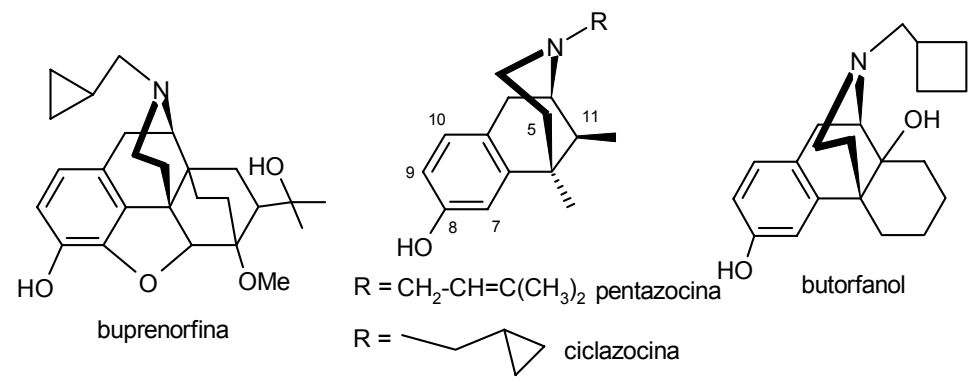

Figura 12. Antagonistas mistos. 
Ferreira, D. T.; Faccione, M.

Tabela 1. Seletividade dos Opióides nos receptores $\boldsymbol{\mu}, \boldsymbol{\delta}, \boldsymbol{\kappa}, \boldsymbol{\kappa}_{3}$

\begin{tabular}{|c|c|c|c|}
\hline FÁRMACOS & $\begin{array}{c}\mu \text { - Analgesia,euforia,constipação } \\
\text { dependência física e pisíquica, } \\
\text { imunossupressão, depressão respiratória, } \\
\text { vômitos. }\end{array}$ & $\begin{array}{l}\delta \text { - Analgesia, imuno- } \\
\text { estimulação, depressão } \\
\text { respiratória. }\end{array}$ & $\begin{array}{l}\text { ๔ - Analgesia, sedação, } \\
\text { miose, diurese, disforia. }\end{array}$ \\
\hline morfina & +++ & & \\
\hline metadona & +++ & & \\
\hline etorfina & +++ & +++ & +++ \\
\hline levorfanol & ++++ & & NA \\
\hline butorfanol & $\mathrm{AP}$ & NA & +++ \\
\hline buprenorfina & AP & NA & -1 \\
\hline naloxona & --- & - & -- \\
\hline naltrexona & $-1-$ & - & --- \\
\hline diprenorfina & --- & -1 & --- \\
\hline nalorfina & --- & & + \\
\hline pentazocina & $\mathrm{AP}$ & & ++ \\
\hline nalbufina & -- & & +++ \\
\hline etilcetociclazocina & AP & + & +++ \\
\hline
\end{tabular}

Peptídeos Endogenos

\begin{tabular}{c|c|c|c}
\hline metilencefalina & ++ & +++ & \\
\hline leu-encefalina & ++ & +++ & \\
\hline$\beta$-endorfina & +++ & +++ & +++ \\
\hline dinorfina A & ++ & & +++ \\
\hline dinorfina B & + & $*$ & +++ \\
\hline$\alpha$-neoendorina & + & $*$ & \\
\hline endomorfina-1 & +++ & & \\
\hline endomorfina-2 & +++ & $*$ & \\
\hline
\end{tabular}

$(+)=$ Agonista; (-) = Antagonista; (AP) = agonista parcial; (NA) = Não avaliado ou inadequado;

(*) Baixa afinidade e concentração. Dados adaptados (GUNION,2004; FRIES '1995; REISINE, T.; PASTERNAK,1996

\section{Referências}

ALDRICH, J. V. Analgesics. In: ABRAHAM, D. J. Burger's Medicinal Chemistry and Drug Discovery. 5.ed. New York: John Willey and Sons, 1996. v.3, p.321-441.

ANDERSEN, G.; SJOGREN, P.; HANSEN, S. H.; JENSEN, N. H.; CHRISTRUP, L. Pharmacological consequences of long-term morphine treatment in patients with cancer and chronic non-malignant pain. European Journal of Pain, Heidelberg, v.8, n.3, p.263-271, 2004.

BECKER, J.; SCHMIDT ,P.; MUSSHOFF, F.; FITZENREITER, M.; MADEA, B. MOR 1 receptor expression in human brains of drug-related fatalities-a realtime PCR quantification. Forensic Science International, Lausanne, v.140, n.1, p.13-20, 2004.

CAMPANERO, M. A.; GARCIA-QUETGLAS, E.; SADABA, B.; AZANZA, J. R. Simultaneous stereoselective analysis of tramadol and its primary phase I metabolites in plasma by liquid chromatography application to a pharmacokinetic study in humans. Journal of Chromatography A, Amsterdam, v.1031, n.1/2, p.219$228,2004$.

CHEN, T. J. H.; BLUM, K.; PAYTE, J. T.; SCHOOLFIELD, J.; HOPPER, D.; STANFORD, M.; BRAVERMAN, E. R. Narcotic antagonists in drug dependence: pilot study showing enhancement of compliance with SYN-10, amino-acid precursors and enkephalinase inhibition therapy. Medical Hypotheses, Livingstone, v. 63, n.3, p.538-548, 2004.

CHRISTOFFERS, K. H.; LI, H.; KEENAN, S. M.; HOWELLS, R. D. Purification and mass spectrometric analysis of the $1 / 4$ opioid receptor. Molecular Brain Research, Amsterdam, v.118, n.1/2, p.119-131, 2003.

CLAROT, F.; GOULLE, J. P; VAZ, E.; PROUST, B. Fatal overdoses of tramadol: is benzodiazepine a risk factor of lethality ? Forensic Science International, Lausanne, v.134, n.1, p.57-61, 2003.

CLAROT, F. PIERRE, G. J. ;VAZ, E.; PROUST, B. Tramadolbenzodiazepines and buprenophine-benzodiazepines: two potential fatal cocktails? Journal of Clinical Forensic Medicine, London, v. 10, p.125-128, 2003.

CONTET, C.; KIEFFER, B. L. BEFORT, K. Mu opioid 
receptor: a gateway to drug addiction .Current Opinion in Neurobiology, London, v.14, n.3, p.370-378, 2004.

CRAFT, R. M.; MCNIEL, D. M. Agonist/antagonist properties of nalbuphine, butorphanol and (-)-pentazocine in male vs. female rats. Pharmacology, Biochemistry and Behavior, Fayetteville, v.75, n.1, p.235-245, 2003.

DAVIDS, E.; GASTPAR, M. Buprenorphine in the treatment of opioid dependence. European Neuropsychopharmacology, Amsterdam, v.14, n.3, p.209216. 2004.

EMMERSON, P. J.; MCKINZIE, J. H; SURFACE, P. L; SUTER, T. M; MITCH, C. H.; STATNICK, M. A. Na ${ }^{+}$ modulation, inverse agonism, and anoretic potency of 4phenylpiperidine opioid antagonists. European Journal of Pharmacology, Amsterdam, v.494, n.2/3, p.121-130, 2004.

EVANS, S. M.; LENZ, G. R.; LESSOR, R. A. Analgesics. Annual Reports in Medicinal Chemistry, San Diego, v.25, p.11-19, 1989.

FARON-GÓRECKA, A.; . KUSMIDER, M.; INAN, S. Y.; SIWANOWICZ, J.; DZIEDZICKA-WASYLEWSKA, M. Effects of tramadol on $\pm_{2}$-adrenergic receptors in the rat brain. Brain Research, Amsterdam, v.1016, n.2, p.263-267, 2004.

FERRARI, A.; COCCIA, C. P. R.; BERTOLINI, A.; STERNIERI, E. Methadone-metabolism, pharmacokinetics and interactions. Pharmacological Research, London, v.50, n.6, p.551-559, 2004.

FRIES, D.S. Analgesics. In: FOYE,W.O.; LEMKE, L.T.; WILLIAMS, D.A Principles of medicinal chemistry. 4. ed New York: Williams \& Wilkins, Media, 1995. Cap. 14

GERRA, G.; BORELLA, F.; ZAIMOVIC, A.; MOI, G.; BUSSANDRI, M.; BUBICI, C.; BERTACCA, S. Buprenorphine versus methadone for opioid dependence: predictor variables for treatment outcome. Drug and Alcohol Dependence, Limerick, v.75, n. 1, p.37-45, 2004.

GUNION, M. W.; MARCHIONNE, A. M.; ANDERSON, C. T. M. Use of the mixed agonist- antagonist nalbuphine in opioid based analgesia. Acute Pain, London, v.6, p.29-39, 2004.

HUTCHINSON, M. R.; SOMOGYI, A. A. (S)-(+)-methadone is more immunosuppressive than the potent analgesic (R)(-)-methadone. International Immunopharmacology, Amsterdam, v. 4, n.12, p.1525, 2004.

JAFFE, J. H.; O'KEEFFE, C. From morphine clinics to buprenorphine: regulating opioid agonist treatment of addiction in the United States. Drug and Alcohol Dependence, Limerick, v. 70, p.S3-S11, 2003. Suppl.

KESKIN, H. L.; KESKIN, E. A; AVSAR, A. E; TABUK, M.;
CAGLAR, G. S. Pethidine versus tramadol for pain relisf during labor. International Journal of Gynecology \& Obstetrics, Amsterdam, v.82, n.1, p.11-16, 2003.

KOROLKOVAS, A. Dicionário terapêutico Guanabara. Rio de Janeiro: Guanabara-Koogan, 1988.

KOROLKOVAS, A.; BURKHALTER, J. H. Química farmacêutica. Rio de Janeiro: Guanabara Koogan, 1988.

KOWALUK, E. A.; ARNERIC, S. P. Novel Molecular Approaches to Analgesics. Annual Reports in Medicinal Chemistry, San Diego, v.33, p.11-20, 1998.

KOWALUK, E. A.; LYNCH, K. J.; JARVIS, M. F. Recent advances in development of novel analgesics. In: BRISTOL, J. A. Annual Reports in Medicinal Chemistry, San Diego, v.35, p.21-30, 2000.

KUGAWA, F.; MATSUMOTO, K.; AOKI, M. Apoptosislike cell death of human breast cancer line MCF-7 induced by buprenophine hydrochloride. Life Sciences, Elmsford, v.75, n.3, p.287-299, 2004.

LEHTONEN, P.; SIREN, H.; OJANPERA, I.; KOSTIAINEN, R. Migration behaviour and separation of tramadol metabolites and diastereomeric separation of tramadol glucuronides by capillary eletrophoresis. Journal of Chromatography A, Amsterdam, v.1041, n.1/2, p.227-234, 2004.

NANOVSKAYA, T.N.; DESHMUKH, S. V.; NEKHAYEVA, I. A.; ZHARIKOVA, O. L; HANKINS, G. D.; AHMED, M. S. Methadone metabolism by human placenta. Biochemical Pharmacology, New York, v.68, n.3, p.583591, 2004.

PAIVA, A.; LOBO, M.; CHAINHO, J. Dependence on tramadol - a cases. European Neuropsychopharmacology, Amsterdam, v.13, Suppl.4, p.S421-S422, 2003.

PANDA, M.; DESBIENS, N.; DOSHI, N.; SHELDON, S. Determinants of prescribing meperidine compared to morphine in hospital patients. Pain, Amsterdam, v.110, n.1/2,p.337-342, 2004.

POIRIER, M. F.; LAQUEILLE, X.; JALFRE, V.; WILLARD, D.; BOURDEL, M. C.; FERMANIAN, J.; OLIE, J. P. Clinical profile of responders to buprenorphine as a substitution treatment in heroin addicts: results of a multicenter study of 73 patients. Progress in Neuro-Psychopharmacology \& Biological Psychiatry, Oxford, v.28, n.2, p.267-272, 2004.

QUAGLIA, M. G.; FARINA, A.; DONATI, E.; COTECHINI, V.; BOSSU, E. Determination of MPTP, a toxic impurity of pethidine. Journal of Pharmaceutical and Biomedical Analysis, Amsterdam, v.33, n.1, p.1-6, 2003,.

REISINE, T.; PASTERNAK, G. Opioid analgesics and 
antagonists. In: GOODMAN; GILMAN' S. The pharmacological basis of therapeutics. 9.ed. New York: Mc-Graw-Hill, 1996. Cap. 23.

REITZ, A. B.; JETTER, M. C.; WILD, K. D.; RAFFA, R. B. Centrally Acting Analgesics. Annual Reports in Medicinal Chemistry, San Diego, v.30, p.11-20, 1995.

SNYDER, S. H. Opiate receptors and beyond: 30 years of neural signaling research. Neuropharmacology, New York, v.47, p.274-285, 2004. Suppl.

SOBEL, B. F. X.; SIGMON, S. C.; WALSH, S. L.; JOHNSON, R. E.; LIEBSON, I. A.; NUWAYSER, E. S.; KERRIGAN, J. H.; BIGELOW, G. E. Open-label trial of an injection depot formulation of buprenorphine in opioid detoxification. Drug and Alcohol Dependence, Limerick, v.73, n.1, p.1122, 2004.

SOIGNIER, R. D.; VACCARINO, A. L.; FANTI, K. A; WILSON, A. M.; ZADINA, J. E. Analgesic tolerance and cross-tolerance to i. c.v. endomorphin-1 endomorphin-2, and morphine in mice. Neuroscience Letters, Limerick, v.366, n.2, p.211-214, 2004.
SPORER, K. A. Buprenorphine: A primer for emergency physicians. Annals of Emergency Medicine, Lansing, v.43, n.5, p.580-583, 2004.

WHITTINGTON, D.; SHEFFELS, P.; KHARASCH, E. D. Stereoselective determination of methadone and the primary metabolite EDDP in human plasma by automated on-line extraction and liquid chromatography mass spectrometry. Journal of Chromatography B, Analytical Technologies in the Biomedical and Life Sciences, Amsterdam, v.809, n.2, p. 13-321, 2004.

WILLETTE, R. E. Analgesic Agents. In: BLOCK, J.; BEALE JR., J. M. Wilson \& gisvold's textbook of organic medicinal and pharmaceutical chemistry. 10. ed. Philadelphia: Lippincott-Raven, 1998. Cap.22

WOODY, G. E.; SENAY,E. C.; GELLER, A.; ADAMS, E. H.; INCIARDI, J. A.; SCHNOLL, S.; MUNOZ, A.; CICERO, T. J. An independent assessment of MEDWatch reporting for abuse/dependence and withdrawal from Ultram (tramadol hydrochloride). Drug and Alcohol Dependence, Limerick, v.72, n.2, p.163-168, 2003.

ZARRINDAST, M. R.; REZAYOF, A. Morphine statedependent learning: sensitization and interations with dopamine receptors. European Journal of Pharmacology, Amsterdam, v.497, n.2, p.197-204, 2004. 